\title{
自律型無人航空機のための地磁気偏角推定に関する研究
}

\section{A Study on Estimation Method of the Magnetic Declination for Autonomous Unmanned Aerial Vehicles}

\author{
正 $\bigcirc$ 中西弘明 (京都大学), 准 金田さやか (京都大学), \\ 正＼cjkstart椹木 哲夫 (京都大学), 准 堀口 由貴男 (京都大学)
}

Hiroaki NAKANISHI, Kyoto University, nakanishi@me.kyoto-u.ac.jp

Sayaka Kanata, Tetsuo Sawaragi and Yukio Horiguchi, Kyoto University

\begin{abstract}
Measurement of the heading which is free from magnetic declination by use of several GPS antennas is widely applied, but it is not suitable for small unmanned aerial vehicles because of its limit of the payload and body length. In this paper, we propose a method to estimate the magnetic declination using an IMU and one GPS antenna. The method consists of 1) estimation of the acceleration of the motion from GPS measurements and 2) estimation of the magnetic declination angle using the estimated accelerations and IMU measurements. We show that the estimation of the magnetic declination angle results in reduced QUEST, that is an eigenvalue problem of $2 \times 2$ real matrix. Experimental results of flight control of an unmanned helicopter demonstrate the effectiveness of the proposed method.
\end{abstract}

Key Words: Magnet Declination, Estimation, Reduced QUEST, Unmanned Aerial Vehicles

\section{1. 緒言}

近年，屋外を自律的に移動する自律ロボットの研究 が盛んに行われている．自律移動ロボットにとって自 己位置同定 (localization) は重要である [1].また、レー ザスキャナーなどにより障害物検知や環境地図を作成 する際には姿勢角計測が特に重要となる。自動車の障 害物検知システムにおいてピッチ角測定に誤差が大き い場合には，障害物までの距離を誤認識することにな る。このために，ジンバル台にレーザスキャナーを取 り付けて前方の観測を行うシステムが導入されている [2]. 姿勢角の計測は自らの制御に大きく関係するだけ でなく，環境認識にも影響を与えるので自律移動ロボッ トでは非常に重要といえる。しかし，地磁気偏角の存在 のために，磁気センサより正確な方位角を知ることは 困難である。このため，[2] では多くの車両が複数 GPS アンテナを用いる GPS コンパスを活用した。

無人航空機も自律ロボットの一種であり，無人航空機 の自律飛行制御に関する研究が盛んに行われている $[3$, $4,5,6]$. その多くは GPS と慣性計測装置 (IMU:Inertial Measurement Unit) を機体に搭載している。また，無人 航空機の適用例として 3 次元地形情報収集システムに ついても研究開発がなされてきた $44,6,7]$. 地磁気偏角 はこれらのシステムに悪影響を与える。しかし，無人 航空機は車両とは異なり，ペイロードやセンサの設置 場所の大きさに制約が大きい。このため, GPS コンパ スの利用による方位角測定は十分とはいえない，そこ で本稿は無人航空機に対して適用可能な磁気偏角を推 定する方法を提案する.

\section{2. 地磁気と座標系}

\section{1 磁気偏角}

地磁気による北および南はそれぞれ磁北 (Magnetic North), 磁南 (Magnetic South) と呼ばれる。これに対し て地球の自転軸に基づいた地理上の北極により定義され る北のことを地理上の北 (Geometric North) あるいは真 北 (True North) と呼ぶが，磁北との間にはずれがある. このずれを地磁気偏角 (Magnetic declination) と呼ぶ，全
地球的スケールで地磁気分布のモデルとしては国際標 準地球磁場 (IGRF: International Geomagnetic Reference Field)が作成されているほか，日本付近の磁気図や近似 式は国土地理院が作成している。地磁気センサを用い て真北からの方位角を決定する場合はこれらの基準を 用いる。

地磁気分布には時間的な変化と局所的な変化がある ことが知られている。例えば，鉄鉱石は地磁気を乱す 効果があるため，局所的な变化の原因となる。，人工物 でいえば鉄が多く使われている建物も同様の効果があ るほか，送電線など磁場を作り出しているものも存在 する。これらの付近では地磁気偏角が参照值と大きく 異なるため，方位磁針により真北を測定する精度が大 きく劣化する。

\section{2 座標系の定義と座標変換}

本節では本稿で用いる座標系の定義を示す，基本的 な表記法は [8]に従う。

- 地球固定座標系 (Earth-Fixed Reference Frame, Earth Frame) $F_{E}$ : 地球の表面の局所座標系. 原点は機体 の近くの点をとり，その点における局所水平面が $x_{E}-y_{E}$ 平面となる。 $x_{E}$ 軸， $y_{E}$ 軸， $z_{E}$ 軸をそれぞ 机真北方向，真束方向，重力方向 (鉛直下向き)を 正にとる.

- 機体中心系 (Vehicle-Carried Vertical Frame) $F_{V}: F_{E}$ 座標系では原点は機体とは離れた別の参照点であっ たが, $F_{V}$ 座標系の原点は機体の質量中心にとる. この座標系は機体とともに運動する。各軸の方向 は $F_{E}$ 座標系と同じである。

- 機体固定系 (Body-Fixed Reference Frame, Body Frame) $F_{B}$ : 原点を機体の質量中心にとる。 $x_{B}$ 軸, $y_{B}$ 軸， $z_{B}$ 軸をそれぞれ機首方向，右翼方向，鉛 直下向きを正にとる。

- 地磁気地球固定座標系 (Geomagnetic Earth Frame) $F_{M}$ : 地球の表面の局所座標系. 原点は機 体の近傍にとる。その点における局所水平面が $x_{M}-y_{M}$ 平面となる。 $x_{M}$ 軸, $y_{M}$ 軸， $z_{M}$ 軸をそ 
れぞれ磁北方向，磁東方向，重力方向 (鉛直下向 き)を正にとる。

\section{$2 \cdot 3$ GPS コンパスによる方位角測定}

GPS コンパスとは少なくとも 2 つ GPS アンテナと それらの相対位置関係から方位角を測定するシステム である。その測定原理を以下に概説する。

いずれか一つの GPS アンテナを基準として他方の GPS アンテナまで引いた直線を基線 (Baseline) と呼ぶ. それぞれのアンテナの位置は異なることから GPS 衛星 からの距離の差, 行路差 (path difference) が生じる。こ の行路差はGPS 電波のキャリア位相差として測定でき るほか, 衛星の位置と基線ベクトルが既知であれば算 出することができる。測定で求めた行路差と計算によ り求めた行路差の差が最も小さくなるような基線べク トルを基線ベクトルの推定值とする。推定した基線べ クトルから方位角を求めることができる。 GPSが準拠 する座標系 WGS-84 は原点は地球の中心にあり，地球 を回転椅円体と近似している。WGS-84の北極は地球 の地理上の北極と一致する。このため, GPS コンパス による方位角測定には地磁気偏角が含まれないことか ら，船舶やUGV(Unmanned Ground Vehicle) において 用いられている。しかし，アンテナの数と同じ GPS 受 信機が必要であることとその測定原理から分かるよう に精度を高めるには基線長が十分な長さが必要である. また，アンテナの相対位置関係が既知かつ固定でなけ ればならない。このため, 市販の GPS コンパスは無人 航空機に利用するには大型かつ重量が大きいという久 点がある。

\section{3. 簡略化 QUEST による地磁気偏角推定}

本稿では単一の GPS アンテナと機体に搭載している 慣性センサにより磁気偏角を推定する方法を提案する. 本手法は，ペイロードが十分ではない小型無人航空機 においても有効である。具体的には，GPSによる測定 值から推定する運動加速度を慣性センサにより算出さ れる運動加速度に変換できる回転行列を求める.さら に, 地磁気偏角推定問題は姿勢角推定法 QUEST を簡 略化した $2 \times 2$ 行列の固有值問題に帰着できることを 示守.

\subsection{QUEST}

ベクトル観測量から姿勢角を推定するWahba's Problem[9] とその解を与える QUEST[10]について説 明玄る。

\section{[Wahba's Problem]}

座標系 $F_{I}$ における $n$ 個の単位ベクトル $\boldsymbol{v}_{i}^{I}(i=$ $1,2, \cdots, n)$ の $F_{I}$ が回転した座標系 $F_{B}$ における観測べ クトルを $v_{i}^{B}$ とする. (1) を最小にする $F_{I}$ から $F_{B}$ の 変換行列 (回転行列) $A$ を求めよ. ただし， $a_{i}$ は重みで あり, $\sum_{i=1}^{n} a_{i}=1$ を満たす正数とする.

$$
L(A)=\frac{1}{2} \sum_{i=1}^{n} a_{i}\left|\boldsymbol{v}_{i}^{I}-A \boldsymbol{v}_{i}^{B}\right|^{2}
$$

\section{[QUEST]}

$$
L(A)=1-\sum_{i=1}^{n} a_{i} \boldsymbol{v}_{i}^{I^{T}} A \boldsymbol{v}_{i}^{B}=1-J(A)
$$

であるから， $L(A)$ の最小化は $J(A)$ の最大化と同じで ある。

$$
\begin{gathered}
J(A)=\sum_{i=1}^{n} a_{i} \operatorname{tr}\left[A \boldsymbol{v}_{i}^{B} \boldsymbol{v}_{i}^{I^{T}}\right]=\operatorname{tr}\left[A B^{T}\right] \\
B^{T}=\sum_{i=1}^{n} a_{i} \boldsymbol{v}_{i}^{B} \boldsymbol{v}_{i}^{I}
\end{gathered}
$$

回転行列 $A$ の要素は9つであるが, 拘束条件が 6 個あ る.このため, $J(A)$ を最大にする変換行列 $A$ を直接求 めるのは困難である。このためQUEST では回転行列 $A$ を表す単位 quaternion $q[11]$ を求める.

$$
q=\left[\begin{array}{c}
\boldsymbol{q}_{v} \\
q_{s}
\end{array}\right]=\left[\begin{array}{c}
\sin (\delta / 2) \boldsymbol{\sigma} \\
\cos (\delta / 2)
\end{array}\right]
$$

ここで， $\boldsymbol{\sigma}$ は回転軸に平行な単位べクトル， $\delta$ はその回 転軸周りの回転角である。回転行列 $A$ は $q$ により

$$
A(q)=\left(q_{s}^{2}-\left|\boldsymbol{q}_{v}\right|^{2}\right) I+2 \boldsymbol{q}_{v} \cdot \boldsymbol{q}_{v}^{T}-2 q_{s}\left[\boldsymbol{q}_{v} \times\right]
$$

と表すことができる. $q$ のベクトル表示 $\boldsymbol{q}^{T}=\left[\boldsymbol{q}_{v}^{T} q_{s}\right]^{T}$ を用いると (3) は，

$$
\begin{gathered}
J(q)=\boldsymbol{q}^{T}\left[\begin{array}{cc}
S-\operatorname{tr} B \cdot I & \boldsymbol{Z} \\
Z^{T} & \operatorname{tr} B
\end{array}\right] \boldsymbol{q}=\boldsymbol{q}^{T} K \boldsymbol{q} \\
\boldsymbol{Z}=\sum_{i=1}^{n} a_{i}\left(\boldsymbol{v}_{i}^{I} \times \boldsymbol{v}_{i}^{B}\right), \quad B+B^{T}=S
\end{gathered}
$$

と変形することができる。ここで $q$ は単位 quaternionで あるので $J(q)$ の最大化問題には $\boldsymbol{q}^{T} \cdot \boldsymbol{q}=1$ なる拘束条 件が付帯されている. Lagrangeの未定乗数法を用いて, 以下の拘束条件無し最大化問題に帰着させる。

$$
\text { maximize } J^{\prime}(\boldsymbol{q})=\boldsymbol{q}^{T} K \boldsymbol{q}+\lambda\left(1-\boldsymbol{q}^{T} \boldsymbol{q}\right)
$$

(9) の解 $\boldsymbol{q}^{*}$ は $\partial J^{\prime}(\boldsymbol{q}) / \partial \boldsymbol{q}=0$ より

$$
K \boldsymbol{q}^{*}=\lambda^{*} \boldsymbol{q}^{*}
$$

を満足する。(10)から明らかなように $\lambda^{*}, \boldsymbol{q}^{*}$ は $K$ の 固有值とその固有ベクトルである。 $J\left(\boldsymbol{q}^{*}\right)=\lambda^{*}$ である から， $K$ の最大固有值 $\lambda_{\max }$ とその固有ベクトル $\boldsymbol{q}_{\max }^{*}$ とすると $J(\boldsymbol{q})$ は $\boldsymbol{q}_{\max }^{*}$ のとき最大值 $\lambda_{\max }$ となる。す なわち, Wahba Problem $の$ 解は $A\left(q_{\text {max }}^{*}\right)$ である.

\subsection{QUEST による磁気偏角推定}

$F_{M}$ と $F_{E}$ は $z$ 軸が共通であり, $F_{M}$ は $z$ 軸を中 心にして地球軸 $F_{E}$ を磁気偏角 $\Delta$ だけ回転させたも のである。したがって， $F_{E}$ から $F_{M}$ への回転を表 す $q$ は $\sigma=[0,0,1]^{T}$, 回転角 $\delta=\Delta$ より, $\boldsymbol{q}=$ $[0,0, \sin \Delta / 2, \cos \Delta / 2]^{T}$ である. このため, 地磁気偏角 推定の場合は $\boldsymbol{p}=[\sin \Delta / 2, \cos \Delta / 2]^{T}$ として 2 次元固 有値問題 (11) に帰着できる.

$$
\left[\begin{array}{cc}
S(3,3)-\operatorname{tr} B & \boldsymbol{Z}(1,3) \\
\boldsymbol{Z}(1,3) & \operatorname{tr} B
\end{array}\right] \boldsymbol{p}=\lambda \boldsymbol{p}
$$

ここで $S(3,3), Z(1,3)$ は (4), (8) で定義された $S$ の $(3,3)$ 成分および $Z$ の $(1,3)$ 成分である. 最大固有値 $\lambda_{\max }$ 
と対応する固有べクトル $\boldsymbol{p}_{\text {max }}$ により磁気偏角 $\Delta$ を求 めることができる.

QUEST で全ての姿勢角を求めるには少なくとも二つ の独立なベクトルのレファレンス $\left(F_{E}\right.$ 表示 $)$ とその観測 値 $\left(F_{M}\right.$ 表示 $)$ が必要である. 小型無人航空機に搭載され るセンサは Strapdown 型 IMU，磁気方位センサ，GPS などがある。

Strapdown 型 IMU および磁気方位センサによれば $F_{B}$ における加速度や角速度から機体姿勢角を求めること ができる。ただし，求めた姿勢角には地磁気偏角が含 まれている，つまり，座標回転を行うことにより加速 度の $F_{M}$ 表示を得ることができる．ただし，観測され る加速度は慣性系から見たものであり，実際の運動に よる加速度だけでなく，重力加速度も付加されている ことに注意する必要がある。

一方，GPS は $F_{E}$ における位置と速度が測定できる。 GPSによると測地系WGS84 における緯度，経度，高 度が出力されるが, 簡単な変換により地球軸 $F_{E}$ にお ける位置および速度が得られる。

以上より，Strapdown 型 IMU と磁気方位センサによ るべクトル観測量は $F_{M}$ 表示, GPS によるベクトル観 測量は $F_{E}$ 表示である。しかし，このままではGPS と IMUではそれぞれ異なるものを測定しているにすぎず, QUEST は適用できない。そこで，GPS 観測值により $F_{E}$ における機体の並進運動の加速度を推定する。加速 度の推定には，加加速度を平均が 0 , 適当な大きさの分 散をもつ白色ガウス雑音と近似した 3 次の線形 Kaman Filter を適用する。

GPS による運動加速度推定の検証のために，[6]で開 発した自律型無人ヘリコプタのテール部に GPS アンテ ナを取り付けて測定を行った結果を示す。実験では，2 周波数利用 RTK-GPS(Novatel 社製 OEM4 シリーズ RT2）を用い，サンプリングレート $20 \mathrm{~Hz}$ で位置・速度を 観測した。観測データから加速度を推定した例を Fig. 1 に示す． 観測データ収集実験は IMU の観測サンプリ ング周期 $200 \mathrm{~Hz}$ に合わせて $5 \mathrm{msec}$ 毎にサンプリングを

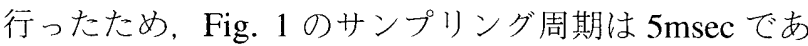
る. 一方, $\boldsymbol{\alpha}(t) の F_{M}$ 表示 $\boldsymbol{\alpha}_{M}(t)$ は Strapdown 型 IMU と磁気方位センサによる観測值から重力加速度を取り 除くことにより算出できる．Fig. 1 にはGPS による運 動加速度推定值だけでなく，IMUの観測結果より算出 した運動加速度も示している。ただし，IMUの結果に は地磁気偏角が含まれている。このため, 厳密にはFig. 1 に示した加速度は異なる座標表示のものである。しか し, 飛行実験場の地磁気偏角が小さかったため, Fig. 1 により加速度推定の検証ができる．Fig. 1 より GPS 観 測量から推定した運動加速度と IMUから算出した運動 加速度は十分に一致することが分かる。よって，GPS により運動加速度 $\boldsymbol{\alpha}(t)$ の $F_{E}$ 表示 $\boldsymbol{\alpha}_{E}(t)$ が推定できる ことが分かる。

以上より，Strapdown 型 IMU と磁気万位センサによ る観測值から算出された $\boldsymbol{\alpha}_{M}(t)(t=0,1, \cdots, T)$, GPS から算出する $\boldsymbol{a}_{E}(t)(t=0,1, \cdots, T)$ をそれぞれの時刻 で大きさが 1 になるように正規化したものを， $\boldsymbol{v}_{t}^{E}, \boldsymbol{v}_{t}^{M}$

$(t=0,1, \cdots, T)$ として $(4),(8)$ を算出することが できるよって，QUESTにより地磁気偏角を推定する ことができることが分かった。

本節で述べた地磁気偏角を推定のために簡略化した QUEST を簡略化 QUEST と呼び, 通常の QUEST と区
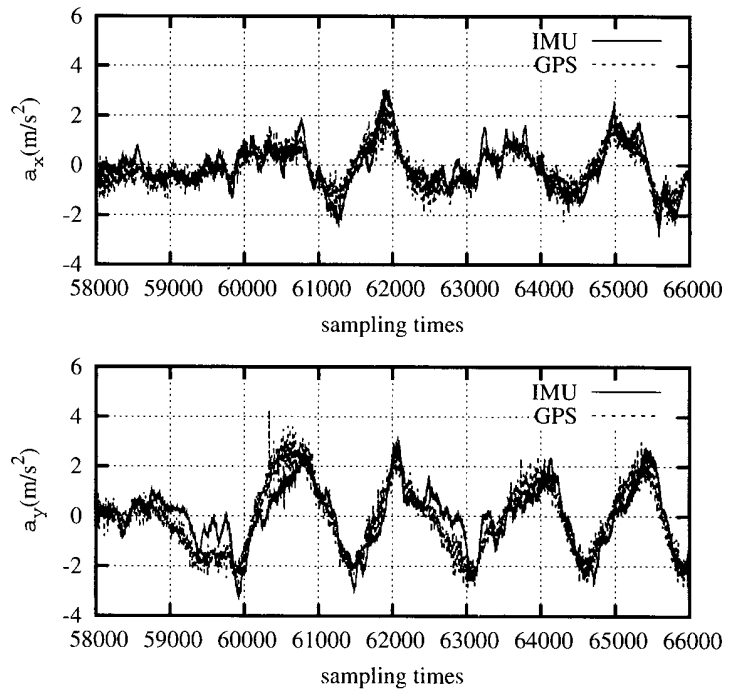

Fig.1 Estimation of acceleration of motion in earth frame $F_{E}$ by Kalman filtering of GPS measurement: Acceleration vector is estimated by Kalman filter in which jerk is assumed to be a white gaussian noise whose average and variance are $0 \mathrm{~m} / \mathrm{s}^{3}$ and $1.0 \mathrm{~m}^{2} / \mathrm{s}^{6}$, respectively.

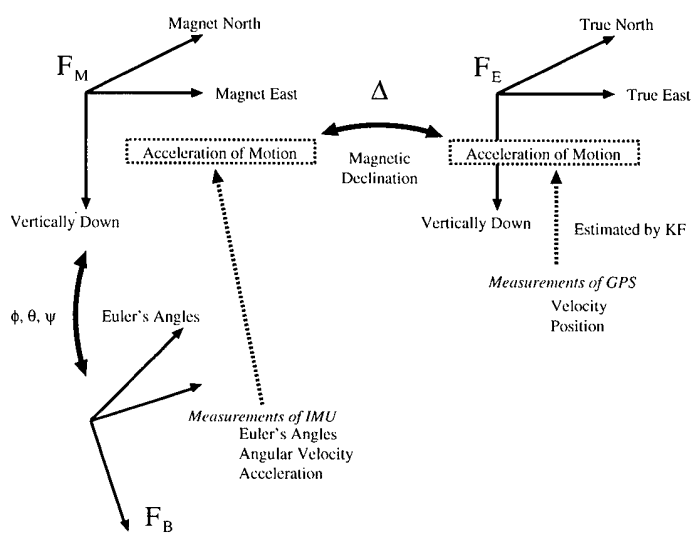

Fig.2 Estimation of magnetic declination by Reduced QUEST: Acceleration of motion in $F_{E}$ is estimated from GPS measurements using linear Kalman filter, and acceleration of motion if $F_{M}$ is calculated from IMU measurements are used as reference vectors in reduced QUEST

別することにする.

\section{4. 実験結果}

本稿で行った実験はすべて京都市伏見区の関西模型 飛行場において実施した。国土地理院やIGRFによると 京都における地磁気偏角は西偏 7 度となっている。地磁 気偏角を表す $\Delta$ は東偏を正とするので $\Delta \approx-7(\mathrm{deg})$ で ある，方向ベクトルが磁北を向く一直線上にある 3 地 点を定め，それぞれの地点の緯度・経度を GPSにより 測定し，真北方向からこの直線の傾きを求めたところ, 地磁気偏角 $\Delta$ は-9.86(deg)であった。

実験に用いた無人航空機は，ヤマハ発動機 (株) 製の産 
Table 1 Estimated magnetic declination by reduced QUEST

\begin{tabular}{|c|c||c|}
\hline$\#$ & Sampling interval of estimation & $\Delta(\mathrm{deg})$ \\
\hline 1 & $7800 \sim 7900$ & -9.57 \\
\hline 2 & $8400 \sim 8460$ & -7.50 \\
\hline 3 & $9200 \sim 9400$ & -8.29 \\
\hline 4 & $9850 \sim 10000$ & -6.28 \\
\hline
\end{tabular}

業用無人ヘリコプタ RMAXをべースに京都大学にて自 律飛行が可能なように開発したものである [6]. RMAX には，ジャイロ・加速度センサが統合されたIMUである YAMAHA Attitude Sensor(以下, YAS と記す)が搭載さ れており，飛行状態を計測することが可能である，YAS を用いることにより，姿勢角，姿勢角速度，加速度を 測定することができる。

実験ではRMAXをマニュアル操作により飛行させた。 実験中の YAS，GPSの観測データは機体のサイドボッ クスに搭載した小型ノートパソコンに保存し，記録さ れたデータを基に数值計算を行った。簡略化 QUESTに よる地磁気偏角推定は水平の運動加速度に基づいて行 うものである。このため，水平方向の加速度がある程 度大きくなければ計算を行うことができない。そこで データ収集のための飛行パターンとして加速と減速を 繰り返し行うものを選んだ。本稿で示す結果は以下の ような条件で行った飛行データを用いて行ったもので ある。

・機首はおよそ北向きとし，運動中は可能な限り変 化させないように操作した。

・移動方向は東西方向としたへヘリコプタは横方向 移動を反復して行った。

IMU，GPS それぞれから推定した運動加速度の水平成 分の 2 乗和 $\alpha_{H}^{2}=\alpha_{x}^{2}+\alpha_{y}^{2}$ を Fig. 3 に示す. 図による と，加速あるいは減速開始時に GPS による加速度推定 值のほうが大きくなっていることが分かる，本実験で はへリコプタはマニュアル操作により飛行を行った。機 首方向はできる限り変化させないように操作を行った が，加速開始あるいは減速開始時に機首方向が変化し ていた. IMUはへリコプタの重心に取り付けられてい るが，GPS アンテナはテール部に取り付けた。つまり, GPS アンテナ位置はへリコプタの重心位置から拈よそ $1 \mathrm{~m}$ ほどのず狆があった。このため GPS アンテナには ヘリコプタの首振り運動に起因する運動成分も観測さ れており，加速度推定にもその運動が含まれることに なった。 その結果として，加速あるいは減速開始時に GPS とIMUによる推定值に誤差が発生したと考えられ る.このような加速度推定の誤差は簡略化 QUEST によ る地磁気推定に影響を与える。そこで，十分な大きさ の加速度がある区間，かつ GPS による加速度推定が十 分であると判断された区間を選んで推定実験を行った。 加速度推定が十分であるかどうかについては， $\alpha_{H}^{2}$ の差 により判断した。 QUEST では推定に用いる各観測べク トルに重み $a_{i}$ があるが，本実験では各推定区間で重み は均一であるとした。簡略化 QUESTにより地磁気偏角 を推定した結果を Table 1 に示す。多少のばらつきがあ るが安定した推定ができていることが分かる。

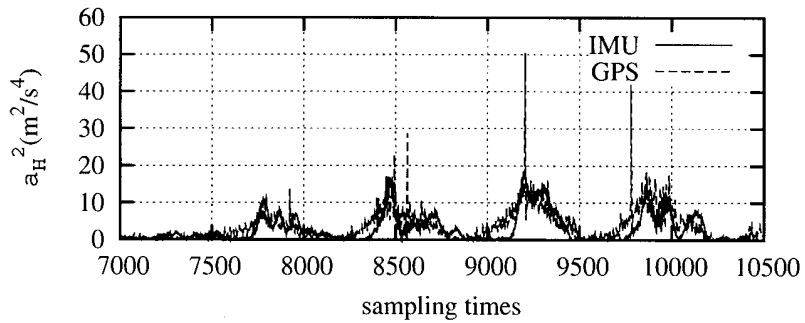

Fig.3 Comparison of estimation of horizontal accelerations

\section{5. 結言}

提案した磁気偏角推定法はぺイロードやスケールに 大きな制約がある小型無人航空機であっても運動加速 度の大きさがある程度以上あれば磁気偏角を推定する ことができる。一般に姿勢角を全て求めるには少なく とも二つの平行ではないベクトルの観測が必要である が，磁気偏角推定に用いる観測ベクトルは平行であっ てもよい。このため，一方向の加速あるいは減速にお ける観測值を用いて推定ができる。また，誤差関数 (1) は $\Delta$ の非線形関数であることため, 最適化には繰り返 し計算による探索が必要であった。これに対して磁気 偏角による回転を表す quaternion を用いることにより， $2 \times 2$ 行列の最大固有值問題に帰着できることから, 計 算量の観点からも長所がある.

\section{文 献}

[1] S. Thrun, W. Burgard and D. Fox: Probabilistic Robotics, MIT Press, 2005.

[2] M. Buehier, K. Iagnemma and Sanjiv Singh: The 2005 DARPA Grand Challenge: The Great Robot Race, Springer-Verlag, 2007.

[3] Ryan Miller, Omead Amidi, and Mark Delouis, "Arctic Test Flights of the CMU Autonomous Helicopter", Proceeding of the Association for Unmanned Vehicle Systems International, 1999.

[4] A. Ollero, S. Lacroix and et al: Multiple Eyes in the skies, IEEE Robotics and Automation Magazine, June, pp. 46-57, 2005.

[5] Akira Sato: Research and Development and Civil Application of an Autonomous,Unmanned Helicopter, Proceedings of AHS International Forum 57, 2001.

[6] 中西弘明, 井上紘一, 佐藤彰: 被災地における空 からの情報収集技術の確立一大大特「空中移動グ ループ」の研究紹介—: 日本ロボット学会学会誌, pp. 546-549, Vol. 22, No. 5, 2004.

[7] J.Ryan Miller: A 3D Color Terrain Modeling System for Small Autonomous Helicopters, 2002.

[8] Bernard Etkin: Dynamics of Atmospheric Flight, John Wiley \& Sons, Inc., 1972.

[9] Wahba, G:"A Least-Squares Estimate of Satellite Attitude", Problem 65.1, SIAM Review, July, pp. 384386, 1966

[10] M. D. Shuster and S. D. Oh: "Three-Axis Attitude Determination from Vector Observations", AIAA J. of Guidance and Control, vol. 4, no. 1, pp. 70-77, 1981.

[11] J. R. Wertz: Spacecraft Attitude Determination and Control, Kluwer Academic Pub, 1978. 